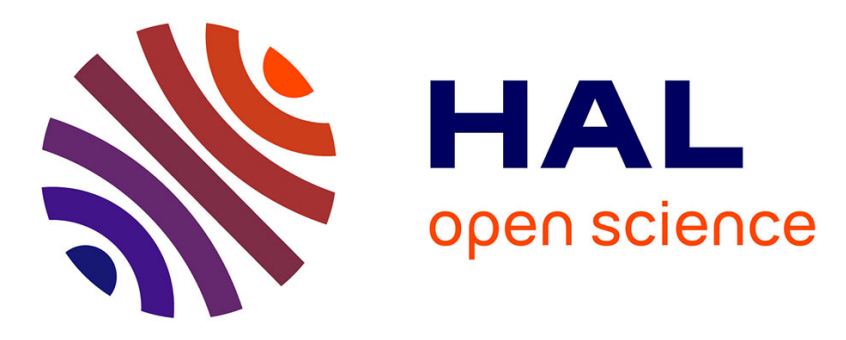

\title{
Dietary n-3 polyUnsaturated fatty acids are capable to enhance protein anabolism response to insulin but not to leucine in old rats
}

Isabelle Savary-Auzeloux, Isabelle Mothe-Satney, Claire Sornet, Dominique Dardevet

\section{To cite this version:}

Isabelle Savary-Auzeloux, Isabelle Mothe-Satney, Claire Sornet, Dominique Dardevet. Dietary n-3 polyUnsaturated fatty acids are capable to enhance protein anabolism response to insulin but not to leucine in old rats. 8. International Symposium on Amino Acid and Protein Metabolism in Health and Disease, Apr 2011, Genova, Italy. 10.1016/j.numecd.2013.10.012 . hal-02746798

\section{HAL Id: hal-02746798 \\ https://hal.inrae.fr/hal-02746798}

Submitted on 3 Jun 2020

HAL is a multi-disciplinary open access archive for the deposit and dissemination of scientific research documents, whether they are published or not. The documents may come from teaching and research institutions in France or abroad, or from public or private research centers.
L'archive ouverte pluridisciplinaire HAL, est destinée au dépôt et à la diffusion de documents scientifiques de niveau recherche, publiés ou non, émanant des établissements d'enseignement et de recherche français ou étrangers, des laboratoires publics ou privés. 
hypothesize that hyperinsulinemia and insulin resistance alone might be important risk factors for cardiovascular disease in children with CKD.

\section{IGF-IR INTERNALIZES WITH CAVEOLIN-1 AND PTRF/CAVIN IN HACAT} CELLS

Barbara Salani ${ }^{\S}$, Mario Passalacqua ${ }^{\notin, \Re}$, Sara Maffioli ${ }^{\S}$, Lucia Briatore Meriem Hamoudane \$, Paola Contini *, Renzo Cordera \$, Davide Maggi ${ }^{\S}$ Department of Endocrinology and Medicine (DiSEM), University of Genova, Genova, Italy

${ }^{E}$ Department of Experimental Medicine (DIMES), Centre of Excellence for Biomedical Research, University of Genova, Genova, Italy

${ }^{*} /$ talian Institute of Biostructures and Biosystems (INBB), University of Genova, Genova, Italy

"Department of Internal Medicine and Medical Specialties (DIMI), University of Genova, Genova, Italy

Background: Insulin like growth factor-I receptor (IGF-IR) is a tyrosine kinase receptor (RTK) associated with caveolae, invaginations of the plasma membrane that regulate vesicular transport, endocytosis and intracellular signaling. IGF-IR internalization represents a key mechanism of down-modulation of receptors number on plasma membrane. IGF-IR interacts directly with Caveolin-1 (Cav-1), the most relevant protein of caveolae. Recently it has been demonstrated that the Polymerase I and Transcript Release Factor I (PTRF/Cavin) is required for caveolae biogenesis and function. The role of Cav-1 and PTRF/Cavin in IGF-IR internalization is still to be clarified.

Methodology/principal findings: We have investigated the interaction of IGFIR with Cav-1 and PTRF/Cavin in the presence of IGF1in human Hacat cells. We show that IGF-IR internalization triggers Cav-1 and PTRF/Cavin translocation from plasma membrane to cytosol and increases IGF-IR interaction with these proteins. In fact, Cav-1 and PTRF/Cavin co-immunoprecipitate with IGF-IR during receptor internalization. We found a different time course of co-immunoprecipitation between IGF-IR and Cav-1 compared to IGF-IR and PTRF/Cavin. Cav-1 and PTRF/Cavin silencing by siRNA differently affect surface IGF-IR levels following IGF1 treatment: Cav-1 and PTRF/Cavin silencing affect significantly IGF-IR rate of internalization, PTRF/Cavin silencing decreases also IGF-IR plasma membrane recovery. Since Cav-1 phosphorylation could have a role in IGF-IR internalization, the mutant Cav-1Y14F lacking Tyr14 was transfected. Cav-1Y14F transfected cells showed a reduced internalization of IGF-IR compared with cells expressing wild type Cav-1. Receptor internalization was not impaired by Clathrin silencing. These findings support a critical role of caveolae in IGF-IR intracellular traveling.

Conclusions/significance: These data indicate that Caveolae play a role in IGF-IR internalization. Based on these findings, Cav-1 and PTRF/Cavin could represent two relevant and distinct targets to modulate IGF-IR function.

\section{EFFECTS OF LEUCINE AND CREATINE SUPPLEMENTATION ON INSULIN} SENSITIVITY OF RATS TREATED WITH DEXAMETHASONE

Humberto Nicastro ${ }^{2}$, Desire F. Coelho ${ }^{1,2}$, Claudia R. da Luz ${ }^{2}$, Daniela F. Seixas ${ }^{2}$, Antonio H. Lancha, ${ }^{1,2}$

${ }^{1}$ Institute of Biomedical Sciences, Department of Biology, University of São Paulo, SP, Brazil

${ }^{2}$ Laboratory of Applied Nutrition and Metabolism, Physical Education and Sports School, University of São Paulo, SP, Brazil

We aimed to evaluate the effects of leucine (Leu) and creatine (Cr) supplementation on dexamethasone (DEXA) treated animals on insulin sensitivity (IS). Adult male Wistar rats were randomly divided into DEXA, DEXA + Leu (DEXA-Leu), DEXA + Cr (DEXA-CR) and Control par-fed group. DEXA-treated groups received $5 \mathrm{mg} / \mathrm{kg} / \mathrm{d}$ for 7 days; DEXA-LEU group received $0.135 \mathrm{~g} / \mathrm{kg} /$ $\mathrm{d}$ of Leu; DEXA-CR group received $5 \mathrm{mg} / \mathrm{kg} / \mathrm{d}$ of $\mathrm{Cr}$. Blood samples were collected for measuring plasma glucose and insulin levels. Plantaris muscle was removed for protein expression. Fasting glycemia was significantly increased in DEX group when compared with CON-PF group $(5.2 \pm 0.2 \mathrm{mmol} / \mathrm{L}$ in DEX group vs. $7.9 \pm 0.3 \mathrm{mmol} / \mathrm{L}$ in CON-PF group; $\mathrm{p}<0.05$ ) and both Leu and $\mathrm{Cr}$ supplementation aggravated such effect $(16.1 \pm 0.9 \mathrm{mmol} / \mathrm{L}$ in DEX-LEU group and $15.1 \pm 1.0 \mathrm{mmol} / \mathrm{L}$ in DEX-CR group; $\mathrm{p}<0.001 \mathrm{vs.} \mathrm{DEX} \mathrm{and} \mathrm{CON-PF}$ groups). Plasma insulin showed the same result pattern observed in fasting glucose $(37.1 \pm 1.5 \mu \mathrm{U} / \mathrm{ml}$ in DEX group vs. $15.2 \pm 0.9 \mu \mathrm{U} / \mathrm{ml}$ in CON-PF group; $\mathrm{p}<0.05 ; 65.7 \pm 10.0 \mu \mathrm{U} / \mathrm{ml}$ in DEX-LEU group and $53.5 \pm 1.7 \mu \mathrm{U} / \mathrm{ml}$ in DEX-CR group; $\mathrm{p}<0.05 \mathrm{vs.}$. DEX and CON-PF groups). HOMA-IR demonstrated decreased IS in DEX group when compared with CON-PF group $(12.7 \pm 3.0 \mathrm{DEX}$ group vs. $1.9 \pm 0.13$ CON-PF group; $\mathrm{P}<0.01)$ and Leu and $\mathrm{Cr}$ supplementation aggravated this response (47.7 \pm 4.9 DEX-LEU group and $39.6 \pm 1.3$ DEX-CR group; $p<0.05$ vs. DEX and (ON-PF groups).
DEX group displayed reduced GLUT4 translocation when compared with CON-PF $(\mathrm{p}<0.05)$ group and Leu and $\mathrm{Cr}$ supplementation increased this response $(\mathrm{p}<0.05$ vs. DEX and CON-PF groups). In conclusion, Leu and $\mathrm{Cr}$ supplementation worsened IS and glucose homeostasis through impairment in GLUT4 translocation.

EFFECT OF AEROBIC EXERCISE AND AMINO ACID SUPPLEMENTATION ON MTORC1 SIGNALING AND MUSCLE PROTEIN SYNTHESIS IN OLDER ADULTS

Melissa M. Markofski ${ }^{1}$, Kyle L. Timmerman ${ }^{1,2}$, Christopher S. Fry ${ }^{2}$, Blake B. Rasmussen ${ }^{1,2}$, Elena Volpi ${ }^{1,3}$

${ }^{1}$ Sealy Center on Aging, Division of Geriatrics, University of Texas Medical Branch, Galveston, Texas, USA

${ }^{2}$ Division of Rehabilitation Sciences, Division of Geriatrics, University of Texas Medical Branch, Galveston, Texas, USA

${ }^{3}$ Department of Internal Medicine, Division of Geriatrics, University of Texas Medical Branch, Galveston, Texas, USA

In otherwise healthy older adults, sarcopenia is defined as decreased muscle mass, strength, and function. Several treatments have been proposed for sarcopenia, including exercise and protein supplementation. The purpose of this preliminary study was to examine if aerobic exercise and/or leucineenriched essential amino acid ingestion can increase skeletal muscle mammalian target of rapamycin complex 1 (mTORC1) signaling and protein synthesis in older adults.

Methods: 18 sedentary $(<7500$ steps/d) but otherwise healthy non-diabetic older adults (68-81 years) completed an acute double-blind randomized study. After a baseline postabsorptive period, subjects rested in bed (REST) or completed 45 min of walking exercise ( $\sim 70 \%$ of HR reserve) on a treadmill (EX), and immediately consumed either a leucine-enriched essential amino acid (EAA) or placebo (PLA) beverage. Stable isotopic techniques and immunoblotting procedures were performed on muscle biopsies collected from a small subset of subjects at baseline, 1 hour, and 3 hours post-treatment to determine mixed muscle fractional synthetic rate (FSR) and phosphorylation status of the mTORC1 signaling pathway.

Preliminary results: FSR and mTOR phosphorylation were enhanced 1.4-fold and 4.0-fold, respectively, in the EAA+EX group.

Conclusion: Aerobic exercise combined with essential amino acid supplementation may be useful in the prevention of sarcopenia. Completion of this study will include measuring all components of the mTORC1 signaling pathway, and adding significantly more subjects to the data set will help to elucidate the independent and combined effects of aerobic exercise and essential amino acid supplementation.

Funded by NIH/NIA grant \#R01AG030070

DIETARY N-3 POLYUNSATURATED FATTY ACIDS ARE CAPABLE TO ENHANCE PROTEIN ANABOLISM RESPONSE TO INSULIN BUT NOT TO LEUCINE IN OLD RATS

Isabelle Savary-Auzeloux ${ }^{1}$, Isabelle Mothe-Satney ${ }^{2}$, Claire Sornet ${ }^{1}$, Dominique Dardevet ${ }^{1}$

${ }^{1}$ INRA, Centre Clermont-Ferrand - Theix, UMR 1019 Unité de Nutrition Humaine, F-63122 Saint-Genès-Champanelle, France, Univ Clermont 1, UFR Médecine, UMR 1019, Unité Nutrition Humaine, F-63001 Clermont-Ferrand, France

${ }^{2}$ Université de Nice-Sophia Antipolis, Faculté de Médecine, Nice F-06107, France; INSERM, U907, IFR50, Nice F-06107, France

Ageing is characterized by sarcopenia partially explained by a decreased sensitivity of protein metabolism to anabolic stimuli such as insulin or amino acids (leucine). Animals fed a n-3PUFA-enriched-diet have shown an increased of whole body protein metabolism sensitivity to insulin in bovine (Gingras et al.2007) associated with an increased of signalling pathways linked to protein metabolism (i.e mTOR). Smith et al, 2011 have confirmed that $n$-3PUFA also improved mTOR signalling pathways in elderly muscle. However, in this former study, the effect on insulin relatively to amino acid sensitivity remains unknown since the improvement of muscle protein synthesis was shown under a hyper-aminoacidemic-hyperinsulinic clamp. The present work aimed at demonstrating if protein metabolism sensitivity to insulin alone and/or amino acids (leucine) alone was improved in old rat muscle with a chronic $n$-3PUFA supplementation. 30 rats ( 16 month-old) were submitted to a control diet or a n-3PUFA enriched diet for 4 months. The response of muscle protein synthesis and proteolysis to insulin $(0,1,5,75 \mathrm{nM})$ or to leucine $(0,100,200 \mu \mathrm{M})$ was measured in vitro on epitrochlearis muscles. Our results showed that protein synthesis stimulation or proteolysis inhibition by leucine was not changed when animals were dietary supplemented 
with n-3PUFA. Contrarily, insulin stimulation of protein synthesis was significantly increased by $\approx 22 \%$ with n-3PUFA compared to controls. Consequently, the increased response of muscle protein synthesis in n-3PUFA supplemented elderly observed by Smith et al (2011) may be explained by an increased response to insulin but not to leucine.

\section{GLUTATHIONE (GSH) DEGRADATION IN PERIPHERAL TISSUES OF PATIENTS WITH CHRONIC KIDNEY DISEASE (CKD)}

I. Mannucci, L. Cappuccino, A. Valli, A. Sofia, R. Russo, A. Bonanni, D. Verzola, G. Garibotto

Department of Internal Medicine and Cardionephrology, Azienda

Universitaria Ospedale San Martino, University of Genoa, Italy

Skeletal muscle is a major body reserve for glutathione (GSH) a major antioxidant. Previous data from our laboratory suggest that peripheral tissues may play a role greater than previously supposed in GSH degradation and in the GSH supply to the kidney, where it is hydrolyzed to Cysteine. The sites and mechanisms responsible for the homeostasis of GSH plasma levels in patients with CKD are not known.

In this study we used the forearm balance technique to get insight into the muscle exchange of GSH and Cysteinylglycine (Cys-Gly, a GSH-related peptide) in 18 CKD patients (age $55 \pm 6$, creatinine clearance $21 \pm 5 \mathrm{ml} / \mathrm{min}$, $15 \mathrm{M} / 3 \mathrm{~F}$, BMI $25 \pm 3$ ), 9 patients on haemodialysis (age $62 \pm 9$, BMI $24 \pm 6$, $6 \mathrm{M} / 3 \mathrm{~F}$ ) and 6 controls (age $45 \pm 4$, BMI $23 \pm 4,4 \mathrm{M} / 2 \mathrm{~F}$ ). GSH and Cys-Gly were measured by HPLC. Plasma flow was measured by strain-gauge plethysmography. Data are expressed as $\mathrm{nmol} / \mathrm{min} / 100 \mathrm{ml}$.

In patients with CKD arterial levels for Cys-Gly and GSH were increased by $123 \%$ and $67 \%$, respectively, with respect to controls $(p<0.05-0.01)$. Both $\mathrm{GSH}$ and Cys-Gly were significantly greater in the forearm vein than in the artery $(p<0.04)$, indicating the occurrence of a significant GSH breakdown and release from muscle cells. The release of both GSH and Cys-Gly from peripheral tissues was similar in CKD and control subjects $(12 \pm 3$ and $9 \pm 4$ $\mathrm{nmol} / \mathrm{min} .100 \mathrm{ml}$, respectively, $\mathrm{p}=\mathrm{NS}$ ). The GSH release was closely associated with the release of Cys-Gly. Arterial plasma GSH and Cys-Gly were directly related to peripheral release of the same aminothiol $\left(r^{2}=0.5\right.$ and $\left.r^{2}=0.25\right)$, respectively suggesting that production from periphery plays a major role on plasma aminothiol levels.

These data indicate for the first time that GSH degradation in skeletal muscle is a major contributor to circulating antioxidants in humans. Cys-Gly and to a lesser extent, GSH itself, take part to an inter-organ process finalized to the conservation of the antioxidant supply to tissues. Although muscle GSH degradation and is not increased in uremia, the supply of this antioxidant to the circulation may insufficient in conditions associated with oxidative stress.

\section{EFFECT OF PROTEIN-ENERGY WASTING (PEW) ON MUSCLE PROTEIN METABOLISM AND OXYGEN CONSUMPTION IN PATIENTS WITH END-STAGE RENAL DISEASE (ESRD)}

Alice Bonanni, Antonella Sofia, Laura Cappuccino, Irene Mannucci, Stefano Saffioti, Daniela Verzola, Giacomo Garibotto Department of Internal Medicine and Cardionephrology, Azienda Universitaria Ospedale San Martino, University of Genoa, Italy

PEW is associated with muscle dysfunction and excess mortality in ESRD patients. However the mechanisms causing wasting have been scarcely studied in humans. In addition, to what extent the microinflammatory state associated with uremia affects the individual determinants of protein turnover has not been specifically studied so far. In the present study, we measured protein synthesis (PS) and degradation (PD) (2H-phe kinetics) and oxygen (O2) uptake across the forearm in 58 subjects. Forearm protein turnover was studied in patients with CKD stage IV $(n=16$-unresticted dietand $n=13$ under low protein diets), in hemodialysis-treated patients with ESRD ( $n=17$, of whom 10 were protein-calorie wasted), and in 12 controls (C). Amino acids were determined by an amino acid analyzer, while phenylalanine isotopic enrichments by GC/MS. Blood flow across the forearm was determined by strain-gauge plethysmography. Data are given in nmol/ min. $100 \mathrm{ml}$ forearm.

Both patients and $C$ were in negative protein balance with $P D$ rates greater than PS $(\mathrm{p}<0.03-0.01)$. In CKD patients under unrestricted diets muscle PS and PD, as well as net protein balance (NP), tended to be lower than in $C$ $(P D=41 \pm 2, P S=26 \pm 1, N B=-12 \pm 1$ vs $P D=45 \pm 2, P S=29 \pm 1, N B=-16$ in $C, \mathrm{p}>0.05)$, and were not significantly affected by the occurrence of microinflammation (defined by CRP $>10 \mathrm{mg} / \mathrm{l}, \mathrm{n}=6$ ). In CKD patients under a low protein diet muscle protein turnover and net protein balance were overall decreased by $30 \%$ ( $\mathrm{p}<0.05$ vs $\mathrm{C}$ ). In ESRD patients in good nutritional conditions $(n=7)$, rates of forearm muscle protein turnover $(P D=42 \pm 3$, $\mathrm{PS}=26 \pm 2, \mathrm{NB}=-16 \pm 1$ ) were also similar to $\mathrm{C}$. On the contrary, ESRD patients with $\mathrm{PEW}$ and microinflammation showed an overall decrease in muscle protein turnover with a greater fall in PS $(-45 \%, \mathrm{p}<0.05)$ than in PD $(-15-20 \%)$. 02 uptake was directly associated with PS in all groups. 02 uptake by the forearm was in PEW+inflammation patients also markedly decreased $(-30 \%, p<0.05)$ in accordance with lower rates of PS. Our data show that in patients with ESRD, while microinflammation per se is not associated with changes in muscle protein metabolism, PEW and microinflammation combine to blunt muscle turnover rates. This defect in protein metabolism can explain the accelerated wasting observed in patients with the complex $\mathrm{PEW} /$ inflammation and their decreased response to food.

\section{DEFECTIVE INSULIN/IGF-I SIGNALING AND LOSS OF MYONUCLEI IN} SKELETAL MUSCLE OF PATIENTS WITH CHRONIC KIDNEY DISEASE (CKD)

D. Verzola, I. Mannucci, A. Sofia, A. Bonanni, V. Cademartori, S. Saffioti, G. Garibotto

Department of Internal Medicine, Nephrology Division, Genoa University, Italy

Studies in animals have shown that uremia interacts with IRS signaling, leading to defective AKT phosphorylation, and that this process may lead to caspase activation and accelerated proteolysis. In a previous study, we observed that apoptotic loss of myonuclei is enhanced in CKD-Stage 5 patients and that this finding couples with defective AKT phosphorylation, suggesting that altered insulin signalling is responsible for defective regeneration of muscle myofiber. In this study we evaluated the occurrence of cell loss by apoptosis, as well as of changes in myostatin gene expression and MAPKrelated cellular signaling in muscle biopsies of patients with advanced CKD. Apoptosis (anti-ssDNA Ab), Myostatin and IL-6 (RT-PCR and immunohistochemistry), as well as phosphorylated (p)-JNK, p-38, p-c-JUN and p-AKT (RT-PCR and immunohistochemistry) were evaluated in muscle biopsies (rectus abdominis) from CKD patients $(n=15)$, taken during the placement of a peritoneal dialysis catheter and in 12 control subjects.

In patients with CKD, muscle fibre cross sectional area (CSA) was lower in patients $(-30 \%, p<0.05)$, while Myostatin mRNA expressions was enhanced by $50-70 \%$ (respectively, $\mathrm{p}<0.05-0.01$ ). Skeletal muscle apoptotic cell loss was enhanced $(C K D=12 \pm 4$, Controls $=1.2 \pm 1 \%, p<0.001)$. The $\mathrm{p}$-AKT expression (an index of anabolic hormone signaling) was reduced by $\sim 50 \%$ with respect to controls $(p<0.001)$; in addition, apoptosis was inversely correlated to $\mathrm{p}$-AKT expression $(\mathrm{p}<0.001)$. P-JNK and $\mathrm{p}$-p38 expression were present in the normal muscle at minimal levels. Conversely, $\mathrm{p}$-JNK and p38 were upregulated in CKD patients $(+50-60 \%, p<0.05$ vs $\mathrm{c}$.). Next, we studied the muscle nuclear expression of $\mathrm{p}$-c-Jun, a main substrate of JNK. In control tissue $\mathrm{p}$-c-Jun was expressed in minimal amounts, while the percentage of $\mathrm{p}$-c-Jun positive nuclei was significantly increased in uremic muscle.

These data show that in atrophied skeletal muscle of CKD patients dysregulation of AKT phosphorylation is associated with an upregulation of JNK and p-38 cell signalling, which are implicated in inflammation, apoptosis and insulin resistance.

\section{HIGH ABUNDANCE PLASMA PROTEINS DEPLETION VS. LOW ABUNDANCE} PROTEINS ENRICHMENT: COMPARISON OF METHODS

Renato Millioni ${ }^{1}$, Serena Tolin ${ }^{2}$, Stefano Sbrignadello ${ }^{1,3}$, Gianpaolo Fadini ${ }^{1}$, Lucia Puricelli ${ }^{1}$, Paolo Tessari ${ }^{1}$, Giorgio Arrigoni ${ }^{4}$ ${ }^{1}$ Department of Clinical and Experimental Medicine, University of Padova, Italy

${ }^{2}$ Department of Agricultural Biotechnology, University of Padova, Italy ${ }^{3}$ Institute of Biomedical Engineering, National Research Council, Padova, Italy

${ }^{4}$ Department of Biological Chemistry, University of Padova, Italy

To date, the complexity of the plasma proteome exceeds the analytical capacity of conventional approaches to isolate low abundance proteins that may prove to be informative biomarkers. Only complex multistep separations strategies have been able to detect a substantial number of low abundance proteins $(<100 \mathrm{ng} / \mathrm{ml})$. The first step of these protocols is generally the depletion of high abundance proteins by the use of immunoaffinity column or the low abundance proteins enrichment by the use of solid phase hexapeptides ligand libraries. Here we present a direct comparison of these two approaches. After the immuno-depletion of high abundance proteins or the enrichment of low abundance proteins, the plasma sample was further fractionated by SCX chromatography and analyzed by 